\title{
Free Choline and \\ Glycerophosphorylcholine and Phosphorylcholine Measurement
}

National Cancer Institute

\section{Source}

National Cancer Institute. Free Choline and Glycerophosphorylcholine and

Phosphorylcholine Measurement. NCI Thesaurus. Code C158259.

The determination of the amount of free choline, glycerophosphorylcholine, and phosphorylcholine present in a sample. 